\title{
Relationship of quadriceps femoris muscle strength and endurance with selected anthropometric indices
}

\begin{abstract}
Background: Muscle strength and endurance have been proven to be related with anthropometric indices. This index is believed to be among the determinant of success in exercise performance and plays an important role in matching athletes to appropriate sports. However, information on the relationship between quadriceps femoris muscle (QFM) strength and endurance with measures of anthropometry is scarce. This study evaluated the relationship between QFM strength and endurance with anthropometric indices.
\end{abstract}

Methods: This descriptive observational study involved one hundred and three undergraduate students ( 81 males and 22 females) recruited by convenience sampling method. Body weight, height and body mass index (BMI) were measured using standardized procedures. QFM strength was measured using an adapted cable tensiometer. QFM endurance was measured in seconds using a handheld stop watch as the maximum time to maintain the maximum contraction of quadriceps femoris. Descriptive statistics was used to explore demographic data. Pearson's moment correlation co-efficient was used to test the hypotheses. Alpha level was set at $\mathrm{p}<0.05$.

Results: The result showed that QFM strength had significant positive correlation with each of body weight and height, while there was no significant correlation with BMI. QFM endurance has significant negative correlation with each of body weight and BMI and a significant positive correlation with height.

Conclusion: Sports medicine experts and team coaches should put into consideration individual's body weight, height and BMI during pre-participatory screening in placing prospective athletes to sports or sporting positions requiring repetitive use of QFM where they have a higher likelihood to excel.

Keywords: quadriceps muscle, anthropometry, sports performance
Volume 4 Issue 4 - 2019

John Davidson Okwudili

Department of Physiotherapy, Alex Ekwueme Federal University

Teaching Hospital, Nigeria

Correspondence: John Davidson Okwudili, Department of Physiotherapy,Alex Ekwueme Federal University Teaching Hospital, PMB I 02 Abakaliki, Ebonyi State, Nigeria, Tel +2348032529550, Email davidsonokwudili2@yahoo.com

Received: August II, 2019 | Published: August 20, 2019

\section{Introduction}

Muscle strength and endurance have been proven to be related with anthropometric indices of body weight, height and body mass index (BMI) with almost all physical activities requiring strength and endurance. ${ }^{1}$ The importance of skeletal muscle in maintaining metabolic and functional health is well established with adequate muscle strength seen as a key component to healthy living. ${ }^{2}$ The success of an exercise performance is determined by the strength, power and endurance of the muscle required for the event, ${ }^{3}$ with evaluation of muscle performance encompassing both strength and endurance. $^{4}$

Muscle strength is an important indicator of muscle performance..$^{5}$ It is the quantity of force a muscle can generate with one largest exertion. ${ }^{6}$ It is usually expressed as torque, which is the product of the force exerted by a muscle and its lever-arm length (i.e. the perpendicular distance from the line of action of the force to the joint's center of rotation). It is one component of physical fitness, the others being muscular endurance, cardiovascular fitness, flexibility and body composition. ${ }^{7}$ Factors that affect muscle strength includes age, BMI, gonadal status, physical activity level and nutritional factors. ${ }^{8}$ It can be assessed in isometric, isotonic or isokinetic modes. ${ }^{9}$ Muscle endurance is the capacity of a muscle or a muscle group to produce force to overcome a resistance more than once. ${ }^{10}$ It has been shown to be a key component of physical fitness and having muscle with adequate endurance capability have been shown to improve posture, avoid low back pain, improve athletic ability and musical prowess. ${ }^{11}$
Muscle endurance is very crucial for people who play sports and have to sustain an activity for an extended duration. ${ }^{12}$ Many daily activities require a sustained exertion applied for some time. Thus, muscle endurance is a crucial part of physical performance and must be taken into account during musculoskeletal function assessment. ${ }^{13}$

Anthropometry is defined as the science of measuring the human body in terms of the height, weight and size of the constituents, including skin fold thickness, to examine and compare relative ratio under normal and abnormal conditions. ${ }^{14}$ The sports scientists have encouraged the adoption of anthropometry through numerous researches in the field such that presently, anthropometry in physical education studies has been widely used. ${ }^{15}$ Weight is an organism's body mass and is measured in kilogram. ${ }^{16}$ Height can be defined as the distance from the lowest point to the highest point on an object or part measured in meters. ${ }^{17} \mathrm{BMI}$ or Quetelet Index is defined as the body weight of the individual divided by the square of its height. It is measured in $\mathrm{Kg} / \mathrm{m}^{2}$.

Several studies have shown that muscle strength has been shown to be associated with the indices of anthropometry of weight, height and BMI. ${ }^{18-20}$ Muscle endurance has also been shown to have relationship with anthropometric indices of body weight, height and BMI. ${ }^{21,22}$ Though there have been studies on the relationship between anthropometric indices (body weight, height and BMI) with muscle strength, there is a dearth of knowledge on the relationship between these indices with the QFM strength specifically. Evidence is also lacking on the anthropometric relationship with QFM endurance. Therefore, this study sought to answer the following questions: 
What is the relationship between the selected anthropometric indices and QFM strength? What is the relationship between the selected anthropometric indices and QFM endurance?

\section{Methods}

Research Design: The study was a descriptive Observational study to evaluate the relationship of quadriceps femoris muscle strength and endurance with selected anthropometric indices.

Subject selection: One hundred and three undergraduate students ( 81 males and 22 females) were recruited in the study using convenience sampling technique. The participants were invited to join the study through text messages and e-mail. The participants were constantly followed up and those who showed interest and are willing to participate were scheduled for data collection. The sample size was calculated with the Taro Yamane's formula;

$$
\mathrm{ss}=\mathrm{N} /\left(1+\mathrm{Ne}^{2}\right)
$$

Where ss $=$ sample size,

$\mathrm{N}=$ population size, $\mathrm{e}=$ sampling error $=0.05$. For the purpose of this study, $\mathrm{N}=$.Therefore, $\mathrm{ss}=$.

Inclusion criteria were: Absence of previous history of neuromuscular or skeletal injuries to the dominant lower limb, availability to attend the study. Exclusion criteria were: students who are athletes or who participate in strength training exercise involving the biceps femoral muscle. Two hundred and fifteen students indicated interest to participate in the study. Only a hundred and thirty students were eventually available at the venue of data collection. A hundred and three students met the inclusion criteria and thus participated in the study.

\section{Data collection instruments}

Adapted cable tensiometer (Camry emperors model: ISO9001): This is a device designed to measure the tension of aircraft cables, which has been adapted to measure muscle tension during static muscle actions. It was used to measure the QFM strength. It has a test-retest reliability index of $0.91 .^{23}$

Bathroom weighing scale (Hana model BR 9001: 0-120kg: China): his is a device used to measure the participants' weight. It has a validity and intra-rater reliability index of 0.9 and 0.95 respectively. ${ }^{24}$

Height meter: This was used to measure the participants' height. It is normally made from a ruler and a horizontal headpiece that is sliding and can be adjusted to rest on the top of the head. It has an intrarater and inter-rater reliability of 0.985 and 0.991 respectively, with a validity index of $0.978 .{ }^{25}$

Stopwatch (BISTEC WR 30M: China): This was used to measure the QFM endurance. It is a hand held time piece designed to evaluate the quantity of time passed from a particular time when it is activated to the time when the piece is de-activated It has similar reliability and accuracy compared to electronic timing with an intra-class reliability of $0.988 .{ }^{26}$

Goniometer (Exacta plastic goniometer: 0-180 ${ }^{\circ}$ ): This is an instrument for measuring joint range of movement. It has a concurrent validity and test-retest reliability index of 0.94 and 0.90 respectively. ${ }^{27}$

\section{Procedure for data collection}

\section{Ethical consideration}

An ethical approval was sought and obtained from the institutional Research Ethical Committee. A written informed consent was also obtained from the participants prior to commencement of data collection. The researcher screened each participant for inclusion criteria and the purpose of the study was explained to them.

\section{Demographic Measurement}

The study was carried out at the exercise physiology laboratory. Data was collected on a daily basis (Monday to Friday), making it easy for the participants to choose a convenient time suitable for them to participate.

Body weight was measured to the nearest 0.1 kilogram $(\mathrm{kg})$ using a bathroom weighing scale. The participants were instructed to stand erect and bare footed with weight evenly distributed on the weighing scale. The researcher made sure the pointer was at the zero mark before measurement commences. The researcher took the reading while squatting in front of the participants. The zero mark was checked for accuracy after each reading.

Height measured to the nearest 0.1 meter (m) using a height meter. The participants were asked to remove their footwear and headwear prior to measurement. The researcher ensured that the participants' heel, back and occiput were touching the scale with the participants looking straight ahead with both feet together. The researcher places a ruler on the vertex of the head and took the reading while standing.

Body mass index (BMI) in $\mathrm{kg} / \mathrm{m}^{2}$ : This was computed using the formula: $\mathrm{BMI}=$ Weight $/$ Height $^{2}$

QFM strength was measured in kilogram force (kgf) using an adapted cable tensiometer. The adapted cable tensiometer was attached to a seat with the participant sitting with the knee joint at 90 degree to the floor which was measured with a goniometer. The cable tensiometer strap was then attached to the participant's ankle. The researcher instructs the participant to pull the tensiometer cable to the maximum he or she can. Quadriceps femoris strength was measured as the reading of the cable tensiometer during the maximum pull. The measurement was taken in the nearest 0.1 kilogram force (Kgf).

QFM endurance was measured in seconds (s) using a handheld stop watch as the maximum time to maintain the maximum contraction of quadriceps femoris muscle.

\section{Data Analysis}

The data collected were computed and summarized using the descriptive statistics of mean and standard deviation. Pearson's Product Moment Correlation co-efficient ( $r$ ) was used to determine the correlation between QFM strength and each of weight, height and BMI and also for the relationship between QFM endurance and each of weight, height and BMI. Correlation coefficients were interpreted thus: r-value less than +3.5 or -3.5 was interpreted as low relationship, r-value between +3.5 and 6.5 or between -3.5 to- 6.5 as moderate relationship and r-value higher than +6.5 or -6.5 as high relationship. ${ }^{28}$ Alpha level was set at 0.05 . Statistical analysis was performed using Statistical Package for Social Sciences (SPSS, Chicago, IL, USA). 


\section{Results}

One hundred and three undergraduate students participated in the study. The participants consist of $81(78.6 \%)$ males and $22(21.4 \%)$ female with age range of the participants is 16-30years. The participants have a mean weight of $69.13 \mathrm{~kg}$ (SD 10.50) and a mean height of $1.71 \mathrm{~m}$ (SD 0.07). The mean BMI was $23.74 \mathrm{~m} / \mathrm{kg}^{2}$ (SD 4.00 ).

There was a significant correlation between some anthropometric indices and QFM strength (Table 1). Also, there was a significant correlation between the studied anthropometric indices and QFM endurance (Table 2).

Table I Correlation between anthropometric indices and quadriceps femoris muscle strength

\begin{tabular}{lllll}
\hline Variables & Mean & SD & r-value & p-value \\
\hline +QFMS $(\mathrm{kgf})$ & 20.05 & 3.86 & & \\
Weight $(\mathrm{kg})$ & 69.13 & 10.15 & 0.32 & $0.003^{*}$ \\
Height $(\mathrm{m})$ & 1.17 & 0.07 & 0.46 & $0.002^{*}$ \\
BMI $\left(\mathrm{m} / \mathrm{kg}^{2}\right)$ & 23.74 & 4 & 0.07 & 0.081
\end{tabular}

+ QFMS, quadriceps femoris muscle strength; BMI, body mass index; SD standard deviation; $r$ : pearson's product moment correlation coefficient. * significant at $\mathrm{p}<0.05$

Table 2 Correlation between anthropometric indices and quadriceps femoris muscle endurance

\begin{tabular}{lllll}
\hline Variables & Mean & SD & r-value & p-value \\
\hline tQFME $(\mathrm{s})$ & 49.57 & 20.36 & & \\
Weight $(\mathrm{kg})$ & 69.13 & 10.15 & -0.49 & $0.002^{*}$ \\
Height $(\mathrm{m})$ & 1.17 & 0.07 & 0.36 & $0.001^{*}$ \\
$\operatorname{BMl}\left(\mathrm{m} / \mathrm{kg}^{2}\right)$ & 23.74 & 4 & -0.58 & $0.003^{*}$
\end{tabular}

tQFME: quadriceps femoris muscle endurance; BMI: body mass index; SD: standard deviation; r: Pearson's product moment correlation coefficient, *: Sigificant at $p<0.05$

\section{Discussion}

The findings of this study showed a significant positive relationship between some anthropometric parameters (body weight and height) and QFM strength. This may suggest that individuals with higher body weight and individuals who are taller had greater QFM strength. This finding is in agreement with the findings of Mannion, et al which showed a significant positive relationship between maximal back extensor muscle strength and total body mass in Bristol, United Kingdom. ${ }^{29}$ Also another study found a significant association between leg strength and total body weight and a significant positive relationship between each of grip strength and leg strength with height in Japanese adolescents. ${ }^{30}$ The results of the present study is also in conformity with the findings of a significant positive relationship existing between leg and back muscle strength with body mass and height in Turkish male national judo players. ${ }^{31} \mathrm{~A}$ similar result was established by a study which investigated physical characteristics as predictors of QFM strength in right -legged healthy males between 19-27 years of age in Ibadan, Nigeria. ${ }^{18}$ The result showed a significant positive relationship between height and QFM strength. The findings of this study might thus imply that taller individuals and individuals with higher body weight might perform better and more satisfactorily in sports requiring strong QFM strength than their shorter and lean counterparts.

However, a non-significant relationship was found between BMI and QFM strength. This is surprising when compared to previous related studies. Though it was in agreement with the study that found a non- significant relationship between each of knee flexor muscles and handgrip muscle strength with BMI in Belgian women, however, it disagrees with the findings of a significant positive relationship between isokinetic QFM strength and BMI in the same population. ${ }^{20}$ Noha, et al also reported a significant positive relationship between triceps, quadriceps and abdominal muscles strength with BMI in Egyptian children..$^{32}$ Also, the finding of this study is in contrast with the reports of a significant negative relationship between BMI and leg strength in Japanese adolescents ${ }^{30}$ and that of a significant positive correlation between grip strength and BMI in older adults in the United Kingdom. ${ }^{29}$ This variation in results might be explained by the difference in the muscles examined and the age differences of the populations studied. The finding of this study might imply that differences in BMI will not be of significance in performance in sports that require strong QFM.

Furthermore, the result of this study revealed that body weight and BMI had a significant negative relationship with QFM endurance while height had a significant positive relationship with QFM endurance. This is in consonance with the result of the study which found that body weight and BMI correlated negatively and significantly with isometric back extensor muscle endurance among Nigerian undergraduates, but disagrees with the finding of a significant negative correlation between height and QFM endurance in the same population. ${ }^{21}$ Similarly, another study reported a negative relationship between trunk flexor and extensor muscle endurance with body weight in normal Egyptian young girls. ${ }^{32}$ It also reported a significant positive relationship between trunk extensor muscle endurance and height, though the same study also found out a negative relationship with height and BMI and trunk flexor muscle endurance in the same population. ${ }^{22}$ This variation in results might be as a result of the difference in the muscle studied. The finding of this study might suggest that taller individuals might perform better in sports that require repetitive use of the QFM. The finding may also imply that individuals with higher body weight and BMI value might not be suitable for sports like marathon that require repetitive use of the QFM.

\section{Implication of the study for practice}

The influence of anthropometric indices on QFM strength and endurance has revealed the need for consideration of such indices when selecting individuals in sporting activities requiring strong QFM. Therefore sports educators and practitioners should determine the strength and endurance requirements of any sports before recruiting players.

\section{Author contribution}

All the authors were responsible for reviewing the manuscript critically for intellectual content and approved the final version for publication. $1^{\text {st }}, 2^{\text {nd }}, 3^{\text {rd }}, 4^{\text {th }}$ and $7^{\text {th }}$ authors were responsible for concept and design of the study. $1^{\text {st }}, 4^{\text {th }}, 5^{\text {th }}, 6^{\text {th }}$ and $7^{\text {th }}$ authors were responsible for acquisition of data. $1^{\text {st }}$ and $3^{\text {rd }}$ authors were responsible for analysis and interpretation of data. $1^{\text {st }}, 4^{\text {th }}$ and $7^{\text {th }}$ authors were responsible for drafting the article.

\section{Funding details}


There was no funding for this study.

\section{Acknowledgement}

None.

\section{Conflict of interest}

The authors declare that there is no conflict of interest.

\section{References}

1. Bompa T, Haff G. Periodization: Theory and Methodology of Training. 5th ed. Illinois: Human Kinetics; 2009.

2. Lowndes, J, Carpenter, RL, Zoeller, RF, et al. Association of age with age with muscle size and strength before and after short term resistance training in young adults. J Strength Cond Res. 2009;23:1915-1920.

3. Guyton AC, Hall JE. Textbook of Medical Physiology. 11th ed. Atlanta: Elsevier Inc; 2006.

4. Clarkson, MK, Gilewish, NF. The significance of high lumbar mobility and low lumbar strength for current and future low back pain in adolescents. Spine. 2006;26:2629-2636.

5. Lindle, RS, Metter, EJ, Lynch, NA, et al. Age and gender comparisons of muscle strength in 654 women and men aged 20-93 years. $J$ Appl Physiol. 1997;83:1581-1587.

6. Karatzaferi C, Chinn MK, Cooke R. The force exerted by a muscle cross-bridge depends directly on the strength of the actomyosin bond. Biophys J. 2004;87(4):2532-2544.

7. Corbin CB, Lindsey R, Corbin CB, et al. Concepts of Physical Fitness and Wellness. 4th ed. McGraw Hill Publishers, Iowa; 2001.

8. Cipriani C, Romagnoli E, Carnevale V, et al. Muscle strength and bone in healthy women: effect of age and gonadal status. Int $J$ Endocrinol Metab. 2012;11:325-332.

9. Degache F, Richard R, Edouard P, et al. The relationship between muscle strength and physiological age: A cross- sectional study in boys aged from 11 to 15. Ann Phys Rehabil Med. 2010;53(3):180-188.

10. Voza L. Define strength, power and muscular endurance. Livestrong, California; 2015.

11. Cavazos M. What are the benefits of good muscular endurance? Body mass index: BMI for children and teens. Demand media center for disease control. 2013.

12. Mackenzie B, Cordoza G. Power speed endurance: a skill-based approach to endurance training. Victory Belt Publishing, Las Vegas, Nevada; 2012.

13. Hulsmann M, Quittan M, Berger R, et al., Muscle strength as a predictor of long-term survival in severe congestive heart failure. Eur J Heart Failure. 2004;6:101-107.

14. Mosby's Medical dictionary. 9th ed. Elsevier, Amsterdam. 2009.

15. Leila J. Health-related anthropometric measures in connection with physical fitness factors. 2nd International conference on social science and humanity IPEDR. 2012.

16. Estlander AM, Vanharanta H, Moneta GB, et al. Anthropometric variables, self- efficacy beliefs, and pain and disability ratings on the isokinetic performance of low back pain patients. Spine. 1997;19(8):941947.

17. Steadman's Medical dictionary for the health professions \& nursing. 6th ed. Philadelphia: Lippincolt Williams \& Wilkins; 2008.

18. Hamzat TK. Physical characteristics as predictors of quadriceps muscle isometric strength: a pilot study. Afr J Med Sci. 2001; 30:179-181.

19. Barbat-Artigas S, Plouffe S, Pion C, et al. Toward a sex specific relationship between muscle strength and appendicular lean body mass index. J Cachexia Sarcopenia Muscle. 2013.

20. Hulens M, Vansant G, Lysens R, et al. Study of differences in peripheral muscle strength of lean versus obese women; an allometric approach. Int J Obes. 2001;25:676-681.

21. Ummunah JO, Ibikunle PO, Ezeakunne AC. Relationship between isometric endurance of back extensor muscles and selected anthropometric indices among some Nigerian undergraduates. J Back Musculoskelet Rehabil. 2014;27:291-298.

22. Mahmoud EW, Salem EE, El-Hadidy EI. Correlation between anthropometric measurements and trunk muscle endurance for normal young girls. Trends Appl Sci Res. 2015;10:117-124.

23. Kimura FI, Jefferson LM, Gulick DT, et al. Intra and inter tester reliability of chatillon and microfet hand- held cable tensiometer in measuring force production. J Sport Rehabil. 1996;3:197-205.

24. Yorkin M, Spaccarotella K, Martin BJ, et al. Accuracy and consistency of weights provided by home bathroom scales. BMC Public Health. 2013;13:1194.

25. Sicotte M, Ledoux M, Zunzunegui V, et al. Reliability of anthropometric measures in a longitudinal cohort of patients initiating ART in West Africa. BMC Med Res Methodol. 2010;10:102.

26. Hetzler RK, Stickley CD, Lundquist KM, et al. Reliability and accuracy of handheld stopwatches compared to electronic timing in measuring sprint performance. J Strength Cond Res. 2008;22:1969-1976.

27. Nussbaumer S, Leunig M, Glatthorn F, et al. Validity and test-retest reliability of manual goniometers for measuring passive hip range of motion in femoroacetabular impingement patients. BMC Musculoskelet Disord. 2010;11:194.

28. Gay LR, Mills GE, Airasian P. Educational research competencies for analysis and applications. 8th ed. Pearson Prentice Hall; 2006.

29. Mannion AF, Adams MA, Cooper RG, et al. Prediction of maximal back muscle strength from indices of body mass and fat-free body mass. Rheumatol. 1999;38:652-655.

30. Miyatake N, Miyachi M, Tabata I, et al. Relationship between muscle strength and anthropometric body composition parameters in Japanese adolescents. Health. 2012;4:1-5.

31. Melekoglu T, Ocal D, Baydil B, et al. Muscle strength in relation to body composition in the Turkish male national judo team. Ovidius University Annals, Series Physical Education and Sports. 2012;12:22-24.

32. Noha AK, Hebatallah MK, Zeinab AH. Relation between body mass index percentile and muscle strength and endurance. Egyptian Journal of Medical Human Genetics. 2016;17(4):367-372. 